\title{
FUNGICIDE TREATMENTS FOR STRIPE RUST CONTROL IN SOUTHLAND AND SOUTH OTAGO
}

\author{
P. McCULLOUGH \\ Bayer New Zealand Ltd, Christchurch
}

SUMMARY

Triadimenol $15 \%+$ fuberidazole $2 \%$ as a seed treatment and triadimefon as a foliar spray were applied to three spring sown wheat cultivars, to investigate their effect on the development of stripe rust (Puccinia striiformis). Triadimenol/fuberidazole reduced the initial disease incidence, and suppressed development in one highly susceptible cultivar up to GS 65 . Triadimefon as a single spray application gave good control, although a second application was necessary during anthesis to prevent reinfection. Each spray positively influenced yield, with largest responses from two triadimefon applications.

\section{INTRODUCTION}

In the spring of 1980, stripe rust was identified in New Zealand for the first time on a farm at Otama, near Gore. During that season, stripe rust was discovered through wheat crops in Southland and South Otago, developing to epidemic proportions in several locations. Spraying of infected crops with triadimefon gave control. The disease was observed to over-winter on volunteer wheat during 1981 and recurrance was anticipated.

Overseas, trials indicated both triadimenol applied as a seed treatment and triadimefon as a foliar spray effectively controlled stripe rust (Bayer Technical Reports, unpublished). Trials determined the effect of these fungicides on stripe rust infections on locally grown wheat cultivars.

\section{METHODS}

Replicated split plot trials were sown at two sites in the spring of 1981 comparing three spring wheat cultivars, seed treatments and triadimefon applications. Trial A sown on 29.9.81 was at Clinton, and Trial B at Clydevale, was sown on 28.9.81. Plots were $10 \times 2 \mathrm{~m}$.

TABLE 1: Definition of spray timing treatments, dates and growth stages applied.

\begin{tabular}{lccc}
\hline Applied fungicide & Code & \multicolumn{2}{c}{$\begin{array}{c}\text { Spray application dates } \\
\text { and growth stages } \\
\text { Trial A }\end{array}$} \\
\hline $\begin{array}{l}\text { Early application } \\
\text { on appearance of rust }\end{array}$ & BE & $28.12 .81 / \mathrm{GS} 45$ & $28.12 .81 / \mathrm{GS} 45$ \\
$\begin{array}{l}\text { Early application followed } \\
\text { by late season application } \\
\text { after reinfection }\end{array}$ & BEL & $21.01 .82 / \mathrm{GS} 65$ & $21.01 .82 / \mathrm{GS} 65$ \\
unsprayed & US & & \\
\hline
\end{tabular}

Seed treatments were applied as slurries using $15+2 \mathrm{~g} / 100 \mathrm{~kg}$ seed of triadimenol/ fuberidazole (triad/fub) and $50+50 \mathrm{~g} / 100 \mathrm{~kg}$ of seed of carboxin/thiram (carb/thir). Untreated seed $(\mathrm{U} / \mathrm{T})$ was included as a comparison with the seed treatments. Triadimefon was applied as a foliar spray using a precision knapsack sprayer and a hand-held boom fitted with Tee-jet nozzles applying 220-390 litres/ha at $200 \mathrm{kPa}$. In all Proc. 35th N.Z. Weed and Pest Control Conf. 
instances triadimefon was applied at a rate of $125 \mathrm{~g} / \mathrm{ha}$ on the first appearance of disease, and again as a late season application.

Sprays were applied as main plots within each replicate to determine most effective application times, with seed treatments and cultivars as subplots. Stripe rust was assessed by taking, at random, 10 main tillers/plot and estimating leaf area infected on a 0-5 scale. Growth stages were determined using a decimal key (Zadoks et al 1974).

Yields were determined using a Hege plot combine, harvesting $12.5 \mathrm{~m}^{2} / \mathrm{plot}$. Both trials were harvested on $\mathbf{1 6 . 4 . 8 2}$

\section{RESULTS AND DISCUSSION}

Seedling infection was not observed in either trial, even though all cultivars in the trial were known to be susceptible to stripe rust (Tiritea=highly susceptible), and during late winter and early spring rust was observed freely sporulating on volunteer plants in the vicinity of the trial areas.

In Trial A, triad/fub significantly reduced disease incidence 12 weeks after sowing when compared to carb/thir and $\mathrm{U} / \mathrm{T}$ in all cultivars, while in Trial B, significant differences existed in Takahe and Tiritea.

An assessment of leaf area infected at GS 65 showed an increase in rust had occurred at both sites, with Tiritea sustaining the heaviest infection. Seed treatment differences were still evident in Tiritea at 100 days after sowing, triad/fub significantly reduced leaf area infected at both sites.

TABLE 2: Disease assessments on Trials $A$ and $B$ at GS 45 (28.12.81) and GS 65 (21.01.82).

\begin{tabular}{|c|c|c|c|c|c|}
\hline \multirow[b]{2}{*}{ Cultivar } & \multirow{2}{*}{$\begin{array}{l}\text { Seed } \\
\text { Treatment }\end{array}$} & \multicolumn{2}{|c|}{ Disease Incidence $\S$} & \multicolumn{2}{|c|}{ Leaf Area Infected $\dagger$} \\
\hline & & Trial A & Trial B & Trial A & Trial B \\
\hline \multirow{3}{*}{ Rongotea } & $\mathrm{triad} / \mathrm{fub}$ & $1.2^{*}$ & 0.3 & 0.2 & 0.7 \\
\hline & carb/thir & 3.2 & 0.4 & 0.6 & 0.4 \\
\hline & $\mathrm{U} / \mathrm{T}$ & 3.2 & 0.7 & 0.7 & 0.2 \\
\hline \multirow{3}{*}{ Takahe } & $\mathrm{triad} / \mathrm{fub}$ & $2.2^{*}$ & $0.3^{*}$ & 0.8 & 1.4 \\
\hline & carb/thir & 2.5 & 0.8 & 1.0 & 2.1 \\
\hline & $\mathrm{U} / \mathrm{T}$ & 4.2 & 0.6 & 0.8 & 1.4 \\
\hline \multirow{4}{*}{ Tiritea } & $\mathrm{triad} / \mathrm{fub}$ & $1.5^{*}$ & $0.4^{* *}$ & $1.0^{* *}$ & $1.3 * *$ \\
\hline & carb/thir & 4.2 & 2.0 & 2.6 & 3.1 \\
\hline & $\mathrm{U} / \mathrm{T}$ & 3.0 & 2.7 & 2.4 & 3.8 \\
\hline & $\mathrm{CV} \%$ & 31 & 42 & 27 & 32 \\
\hline
\end{tabular}

$\S$ plant numbers infected $/ 1 \mathrm{~m}$ row, 12 weeks after sowing

$\dagger$ mean leaf infection from flag $+\mathrm{L} 2+\mathrm{L} 3$ index $0=$ nil, $1=0-10 \%, 2=11-25 \%$, $3=26-50 \%, 4=50-75 \%, 5=75-100 \%$ infection. Trace damage in (BE) plots was only from pre-spray infection.

* ** Significantly different from carb/thir and U/T at $\mathrm{P}<0.05$ and $\mathrm{P}<0.01$ comparing differences within cultivars in columns.

In the 24 days between triadimefon applications, rust continued to develop, and at assessment on 17.2.82 almost total leaf infection in the unsprayed plots had occurred (Table 3). Significant differences in rust severity were present between BE and BEL in Takaha $(P<0.05)$ and Tiritea $(P<0.01)$, and analysis of spray differences over all treatments indicated BEL to be highly significant different to $\mathrm{BE}$.

Seed treatment effects within cultivars were not significant at this assessment, with the exception of Tiritea, in which triad/fub showed a lower $(P<0.05)$ rust infection to carb/thir and U/T. 
Analysis of the seed treatment effects for all cultivars $\mathrm{x}$ sprays identified a highly significant $(P<0.01)$ reduction in leaf area infected for triad/fub compared to carb/thir and $\mathrm{U} / \mathrm{T}$.

Yield responses resulted from triad/fub and triadimefon treatments with both $\mathrm{BE}$ and BEL applications, demonstrated a larger yield response when associated with triad/fub seed treatment. Trial design precludes full identification of differences within cultivars, however mean data for Rongotea and Takahe indicated significant yield increases $(P<0.05)$ for triad/fub compared to other treatments over all sprays and cultivars.

Yield response to spraying was identifiable within Tiritea when comparing two sprays to no sprays in all seed treatment categories $(\mathrm{P}<0.01)$, and in Takahe when comparing sprays in triad/fub only.

Overall mean data for BEL and BE applications identified significant $(\mathrm{P}<0.05)$ responses in yield in each seed treatment category, irrespective of cultivar, while BEL prevented yield losses $(P<0.05)$ in all cultivars irrespective of seed treatment.

TABLE 3: Trial A: Leaf area infected on 17.2.82, 27 days after spraying (BEL) at GS 75; and yield relative to cultivars, seed treatments and spray treatments.

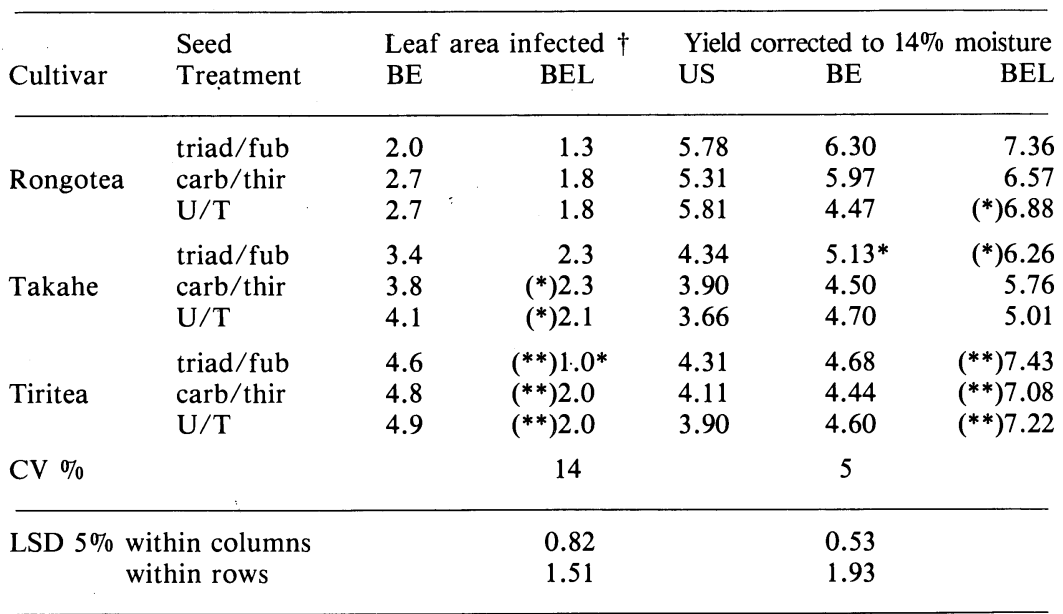

$\dagger$ leaf infection assessed on Flag + L2 + L3 on 0-5 scale. Unsprayed plots were assessed but had $90-100 \%$ leaf damage.

$\left(^{*}\right)\left(^{* *}\right)$ Significantly different from US and BE at $\mathrm{P}<0.05$ and $\mathrm{P}<0.01$ comparing differences within cultivars in rows.

* Significantly different from carb/thir and U/T at $\mathrm{P}<0.05$ comparing differences within cultivars in columns.

As in Trial A, rust in unsprayed plots increased rapidly, and disease severity was $90-100 \%$ leaf area infected at GS 77 (Table 4). Similar also to Trial A, seed treatment effects within cultivars were not readily identifiable, at GS 77, however, in Rongotea triad/fub had less infection $(\mathrm{P}<0.05)$ in both $\mathrm{BE}$ and BEL. Analysis of trial means between all cultivars $x$ spray treatments indicated less $(P<0.05)$ infection in triad/fub compared to carb/thir and U/T.

Seed treatment effects on yield within cultivars are not significant. . However, analysis of mean data for, seed treatments $\mathrm{x}$ sprays $\mathrm{x}$ cultivars indicated overall trial significance $(P<0.05)$ for yield response from seed treatment.

Both $\mathrm{BE}$ and $\mathrm{BEL}$ applications gave yield responses $(\mathrm{P}<0.05)$ within each cultivar, for each seed treatment. 
TABLE 4: Trial B leaf area infected on 17.2.82 (GS77), 26 days after spraying (BEL) at GS 73, and yield relative to cultivars, seed treatments and spray treatments.

\begin{tabular}{|c|c|c|c|c|c|c|}
\hline \multirow[b]{2}{*}{ Cultivar } & \multirow{2}{*}{$\begin{array}{l}\text { Seed } \\
\text { Treatment }\end{array}$} & \multicolumn{2}{|c|}{ Leaf area infected $\dagger$} & \multicolumn{3}{|c|}{ Yield corrected to $14 \%$ moisture } \\
\hline & & $\mathrm{BE}$ & BEL & US & $\mathrm{BE}$ & $\mathrm{BEL} \S$ \\
\hline \multirow{3}{*}{ Rongotea } & triad/fub & $2.2^{*}$ & $2.1^{*}$ & 5.63 & $\left({ }^{*}\right) 8.35$ & $(*) 8.47$ \\
\hline & $\mathrm{carb} /$ thir & 3.0 & 2.9 & 5.55 & $(*) 8.23$ & $(*) 8.95$ \\
\hline & $\mathrm{U} / \mathrm{T}$ & 2.8 & 2.5 & 4.71 & $(*) 7.75$ & $(*) 7.59$ \\
\hline \multirow{3}{*}{ Takahe } & $\mathrm{triad} / \mathrm{fub}$ & 2.7 & $(* *) 1.6$ & 3.27 & $(*) 7.51$ & $(*) 7.90$ \\
\hline & carb/thir & 2.2 & 1.9 & 3.15 & (*)6.44 & $(*) 7.24$ \\
\hline & $\mathrm{U} / \mathrm{T}$ & 2.6 & $(*) 1.8$ & 2.88 & $(*) 7.13$ & $(*) 7.14$ \\
\hline \multirow{3}{*}{ Tiritea } & $\operatorname{triad} / \mathrm{fub}$ & 2.0 & 1.5 & 3.84 & $(*) 8.56$ & $(*) 9.40$ \\
\hline & carb/thir & 1.9 & 1.3 & 2.84 & (*)8.53 & $(* *) 9.35$ \\
\hline & $\mathrm{U} / \mathrm{T}$ & 2.3 & 1.9 & 2.62 & $(*) 7.95$ & $(*) 8.18$ \\
\hline $\mathrm{CV} \%$ & & & 15 & & 10 & \\
\hline \multirow[t]{2}{*}{ LSD $5 \%$} & in columns & & 0.64 & & 1.35 & \\
\hline & hin rows & & 0.67 & & 2.70 & \\
\hline
\end{tabular}

$\dagger$ See Table 2

(*) $(* *)$ Significantly different from US and $\mathrm{BE}$ at $\mathrm{P}<0.05$ and $\mathrm{P}<0.01$ when comparing differences within cultivars in rows.

*** Significantly different from carb/thir and U/T at $\mathrm{P}<0.05$ and $\mathrm{P}<0.01$ when comparing differences within cultivars in columns.

\section{CONCLUSION}

Triadimenol/fuberidazole seed treatment reduced incidence on appearance of disease at 12 weeks after sowing. Subsequent disease development in unsprayed plots was rapid with total leaf infection 7 weeks after initial infection.

Triadimefon applied on appearance of rust prevented reinfection for 3 weeks. A second application during anthesis was required to give continued protection. On Tiritea, rapid post-flowering disease development in BE resulted in a large yield decrease in Trial A, however in Trial B slower post-flowering rust development was reflected in less yield loss in the absence of a second triadimefon application. This may be related to spikelet survival during anthesis, as a large number of poorly filled grains were present with well filled grain from plots not receiving a second spray.

It is suggested that triadimenol/fuberidazole seed treatment be used as an adjunct to triadimefon as a foliar spray, with application on appearance of rust up to completion of anthesis.

\section{ACKNOWLEDGEMENTS}

Bayer New Zealand are grateful to B. Pannett of Clinton and W. McLaughlan of Clydevale for their co-operation and to DSIR Gore for assistance with sowing and harvesting the trials.

\section{REFERENCES}

Zadoks, J.C., Chang, T.T. and Konzak, C.E., 1974. A decimal code for the growth stages of cereals. Weed Research 14: 451-421. 